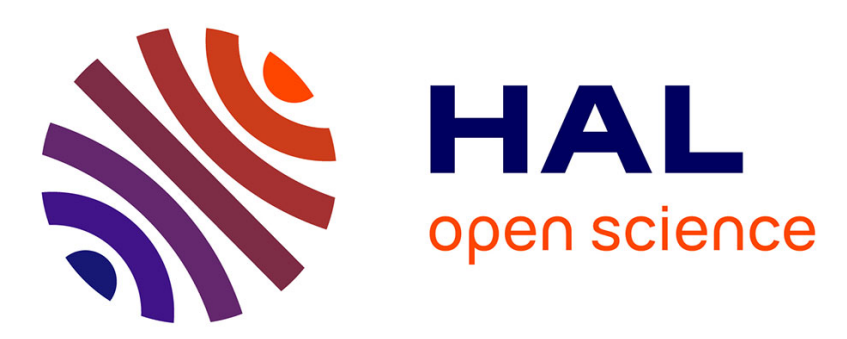

\title{
Risk based inspection of jackets submited to through-wall cracks
}

Franck Schoefs, Mustapha Rguig

\section{To cite this version:}

Franck Schoefs, Mustapha Rguig. Risk based inspection of jackets submited to through-wall cracks. ASME 22nd International Conference on Offshore Mechanics and Arctic Engineering (OMAE2003), 2003, Cancun, Mexico. 10.1115/OMAE2003-37330 . hal-01008852

\section{HAL Id: hal-01008852 \\ https://hal.science/hal-01008852}

Submitted on 29 Sep 2020

HAL is a multi-disciplinary open access archive for the deposit and dissemination of scientific research documents, whether they are published or not. The documents may come from teaching and research institutions in France or abroad, or from public or private research centers.
L'archive ouverte pluridisciplinaire HAL, est destinée au dépôt et à la diffusion de documents scientifiques de niveau recherche, publiés ou non, émanant des établissements d'enseignement et de recherche français ou étrangers, des laboratoires publics ou privés. 


\title{
RISK BASED INSPECTION OF JACKETS SUBMITED TO THROUGH-WALL CRACKS
}

\author{
Schoefs Franck \& Rguig Mustapha \\ Civil Engineering Laboratory of Nantes - St Nazaire \\ 2 rue de la Houssinière \\ F - 44322 NANTES (France) \\ Tel : +33 (0) 151125522 \\ E-mail : schoefs@physique.univ-nantes.fr
}

\begin{abstract}
The actual challenge for the requalification of existing offshore structures through a rational process of reassessment leads to state the importance of Risk Based Inspection methodology. This paper points out the inspection results modelling and their contribution to decision aid tools. The study of the impact of through cracks on structural integrity of jacket platforms is still a challenge. The detection of large cracks is first addressed. In order to minimize inspections and maintenance costs, all the available data from inspection results, such as probability of detection and probability of false alarm, must be addressed, as well as the probability of crack presence. This can be achieved by the use of the decision theory. These capabilities of Non Destructive Testing give a first input for the risk study. A cost function is suggested to introduce this modelling into a risk analysis and is devoted to help rank the NDT tools. The case of large through-wall cracks is specifically addressed.
\end{abstract}

\section{INTRODUCTION}

Fixed offshore platforms such as jackets offer harsh environmental conditions for in situ inspections and are submitted to extreme events. Most of them currently reach or will reach soon their initial design lifetime and need structural integrity assessment from an economical point of view (Moan 2000). Regarding the fatigue effects on jackets platforms, cracks at the weld connection in tubular nodes are propagating. These are surface cracks, which reach the wall thickness with time: this is the through cracks. Then the tube detaches from the node; this is not satisfactory from design criteria point of view where the thickness defines the limit state of crack depth. Through crack is then considered as the critical size. It means that beyond this crack depth, repair is advocated whatever the consequence on the structural behaviour. To avoid such damages, the structure is managed using Inspection, Maintenance and Repair plans ([1]-[5]). In order to optimize costs induced by these plans, research have been carried out: optimization on inspection planning ([6],[7]), Risk-Based Maintenance/Inspections ([1],[8]-[11]) and Reliability Centered Maintenance ([12]). They provide suitable models of inspections results in order to perform mechanical and fatigue computing as well as reliability updating. The definition of probability updating is devoted to this aim. Several challenges which may conflict have to be worked out :

minimize inspections, failure and maintenance costs,

minimize uncertainty on inspection results,

obtain the most complete information on structural integrity. This can be achieved by the mean of mechanical criteria for the ranking of critical nodes and decision aid-tool for the risk based ranking of inspection capability. Moreover, to analyze evolution with time, one must provide probabilistic models of crack growth and methods for inspections updating. This questioning is not treated in this paper.

First, a risk based analysis of inspection performance for offshore structures is proposed. Detection of cracks is of great importance and a miss, or a spurious indication can lead to maintenance costs overrun. In order to minimize inspections and maintain costs, all the available data from inspections results such as probability of detection, probability of false alarm must be used, as well as the probability of crack presence. This can be achieved by the use of the decision theory. In particular the transfer of detection probabilistic information obtained from tests in laboratory to decision aidtool after in-situ inspection is presented.

In a second part, several approaches of NDT tool ranking are compared. First, decisions based on PoD information are 
presented. Then R.O.C curve is introduced as graphical support which contains all the probabilistic information of inspection result. The conditioning on events "detection of crack" and "presence of crack" is inversed in view to provide decision aidtools from in-situ inspection results. It leads to introduce a new probability: the probability of crack presence. Theses concepts are finally illustrated with numerical examples.

\section{PROBABILISTIC MODELING OF CRACK DETECTION}

The detection of cracks in steel offshore jacket structures is a great challenge, first, by the cost induced. Through crack detection is cheaper using F.M.D. (Flooded Member Detection) techniques, than classic ones such as M.P.I, A.C.F.M or Ultrasonic. However the kind of information given is quite different: F.M.D is only able to show whether or not a through crack has been detected whereas other techniques can detect smaller cracks in order to follow or repair them. These cracks do not have the same impact from a structural integrity point of view.

The harsh environment and bad conditions of underwater inspections lead to lower detection performances than in laboratory tests. From the detection point of view, it means that during an inspection campaign, crack detection does not imply crack presence. This is known as the probability of false alarm PFA or false indication, whereas the case of detection of an existing crack is referred to the probability of detection PoD.

If tests are performed in laboratory under ideal conditions, these grandeur are closely linked to those obtained with the signal theory. Then the definition of PoD can be expressed in the following form :

$\operatorname{PoD}(\mathrm{a})=\mathrm{P}\left(\mathrm{a}>\mathrm{a}_{\mathrm{d}}\right)$

Where $a_{d}$ is the detectable crack size, under which it is assumed that no detection is done and $a$ the crack size. More the crack size is great, more the PoD is close to 1 . Figure 1 illustrates the $\mathrm{PoD}_{(\mathrm{lab})}$ and the $\mathrm{PFA}_{(\mathrm{lab})}$ caculated for a low signal/noise ratio of about 2 and a specific detection threshold at 8 . Noise and signal-noise are, for the illustration, supposed to be normally distributed. Negative crack size are due to the noise. The usual definition of PoD is the probability to detect a crack in a crack class range (see below). To obtain a global sight of the NDT tool performance, the $\mathrm{PoD}_{(\mathrm{lab})}$ can be plotted as a function of the $\mathrm{PFA}_{(\mathrm{lab})}$. This is the Receiver Operating Characteristic (abbreviated R.O.C) curve which is the intrinsic tool performance for each crack size (see figure 2). Two R.O.C curves are plotted one for a high signal/noise ratio (about 5 for NDT 2) and the second for a lowest signal/noise ratio (about 2 for NDT 1).

It is to notice that uncertainties on PoD and PFA curve assessment have to be introduced. In fact PoD theoretical curve should be continuous, monotonically increasing as it is a probability distribution function. However, the experimental PoD curve is discrete and not necessarily monotonically increasing. Each point is representative of a crack class range and the probability of detection in that class is the number of actual detected cracks divided by the total number of existing cracks in that class. As a consequence, it is not necessarily an increasing function. In particular, such a curve is representative of complex tubular joint inspections, with inclined braces on the chord and no distinction of shape or geometrical characteristics. As some area of such nodes are less easy to reach for the diver or the R.O.V, the inspection performance decreases: the typology and accessibility of the joint have a great influence on PoD. This shows that the first model (equation (1)) is not satisfactory for inspection data use without evaluation of the uncertainty on PoD. Several authors ([13]) propose a reliable PoD curve or a lower bound estimate of population PoD at $95 \%$ confidence ([14]).

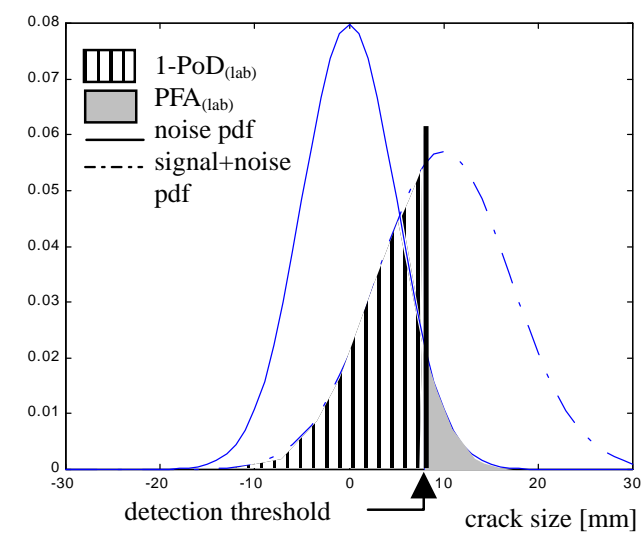

Figure 1. THERORETICAL DEFINITIONS OF POD AND PFA.

Let us note $X$ the random variable that takes the value $X=1$ in case of crack presence, $X=0$ otherwise. To inspect is to make a decision on the state of the inspected area. Thus a detection is modeled by the random decision function $d($.$) on$ the state $X$ of the inspected area: in case of crack detection $d(X)$ $=1$ and otherwise $d(X)=0$. Finally, the probability of detection and the probability of false alarm can be modelled as follows:

$$
\begin{aligned}
& \operatorname{PoD}(X)=P(d(X)=1 \mid X=1) \\
& \operatorname{PFA}(X)=P(d(X)=1 \mid X=0)
\end{aligned}
$$

Considering now in situ inspections, the complex environment and harsh conditions of the divers make generally not optimal the condition of use of N.D.T tools. This leads to lower performances than expected. There is no way actually to provide a function able to deduce the new R.O.C. curve from the previous obtained in laboratory. The only way is to assess directly these characteristics in realistic in-situ conditions. This was made within the ICON project [13]. Moreover the aim of this project was to give an unified overview of several tool performances in the same realistic conditions. 


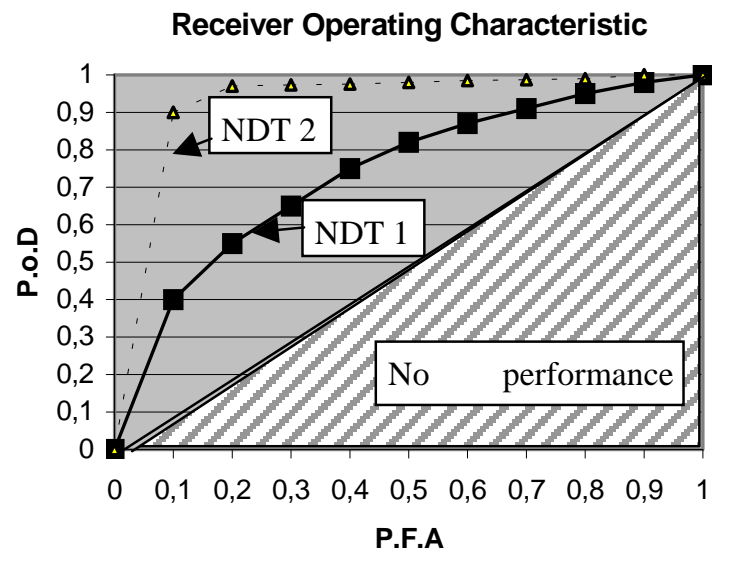

Figure 2. EXAMPLE OF R.O.C. CURVES FOR TWO N.D.T TOOLS AND ONE CRACK SIZE OF 10 MM MEAN.

The decision scheme from inspection results is quite different as this one. In fact the conditioning of events is inversed. The problem is to take a decision on the structural state from an inspection result and not to decide conditionally to a real structural state as it is presented in equations (2) and (3) (see figure 3 ).

The events $E_{i}$ related to crack presence/absence conditionally to crack detection/non-detection are:

- $\mathrm{E}_{1}$ : no presence of crack conditionally to no crack detection,

$P\left(E_{1}\right)=P(X=0 \mid d(X)=0)$

- $\mathrm{E}_{2}$ : no presence of crack conditionally to crack detection,

$\mathrm{P}\left(\mathrm{E}_{2}\right)=\mathrm{P}(\mathrm{X}=0 \mid \mathrm{d}(\mathrm{X})=1)$

- $\mathrm{E}_{3}$ : presence of crack conditionally to no crack detection,

$\mathrm{P}\left(\mathrm{E}_{3}\right)=\mathrm{P}(\mathrm{X}=1 \mid \mathrm{d}(\mathrm{X})=0)$

- $\mathrm{E}_{4}$ : presence of crack conditionally to crack detection,

$P\left(E_{4}\right)=P(X=1 \mid d(X)=1)$

Some events are complementary and :

$\mathrm{P}\left(\mathrm{E}_{1}\right)+\mathrm{P}\left(\mathrm{E}_{3}\right)=1 ; \mathrm{P}\left(\mathrm{E}_{2}\right)+\mathrm{P}\left(\mathrm{E}_{4}\right)=1$

These probabilities are then expressed ([15],[16]) as function of POD (eq. 2), PFA (eq. 3) and PCP, the Probability of Crack Presence :

$$
\mathrm{P}(\mathrm{E} 1)=\frac{(1-\mathrm{PFA}(\mathrm{X})) \cdot(1-\mathrm{PCP}(\mathrm{X}))}{(1-\mathrm{PoD}(\mathrm{X})) \cdot \mathrm{PCP}(\mathrm{X})+(1-\mathrm{PFA}(\mathrm{X})) \cdot(1-\mathrm{PCP}(\mathrm{X}))}
$$

$\mathrm{P}(\mathrm{E} 2)=\frac{\mathrm{PFA}(\mathrm{X}) \cdot(1-\mathrm{PCP}(\mathrm{X}))}{\mathrm{PoD}(\mathrm{X}) \cdot \mathrm{PCP}(\mathrm{X})+\mathrm{PFA}(\mathrm{X}) \cdot(1-\mathrm{PCP}(\mathrm{X}))}$
$\mathrm{P}(\mathrm{E} 3)=\frac{(1-\mathrm{PoD}(\mathrm{X})) \cdot \mathrm{PCP}(\mathrm{X})}{(1-\mathrm{PoD}(\mathrm{X})) \cdot \mathrm{PCP}(\mathrm{X})+(1-\mathrm{PFA}(\mathrm{X})) \cdot(1-\mathrm{PCP}(\mathrm{X}))}$

$\mathrm{P}(\mathrm{E} 4)=\frac{\mathrm{PoD}(\mathrm{X}) \cdot \mathrm{PCP}(\mathrm{X})}{\mathrm{PoD}(\mathrm{X}) \cdot \mathrm{PCP}(\mathrm{X})+\mathrm{PFA}(\mathrm{X}) \cdot(1-\mathrm{PCP}(\mathrm{X}))}$

\section{Inspection results}

Area to be inspected good detection bad detection

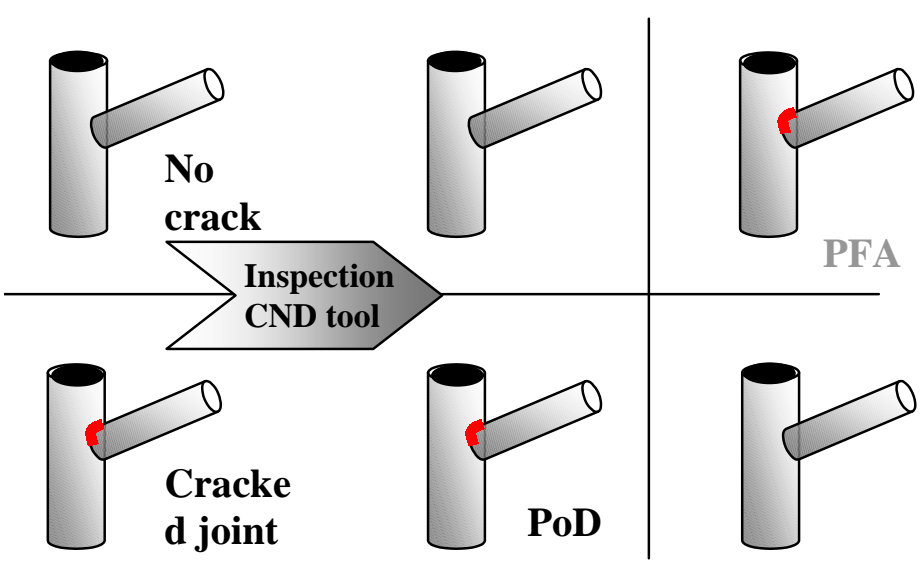

Figure 3. CASES OF CRACK PRESENCE/ABSENCE CONDITIONALLY TO DETECTION/NON DETECTION.

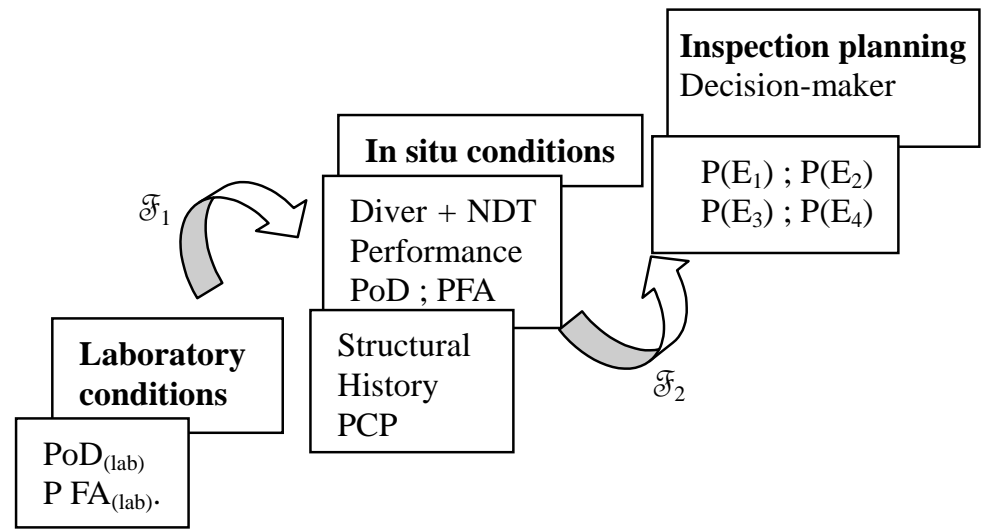

Figure 4. TRANSFER OF DETECTION DATA IN THE DECISION CHAIN.

where $\mathscr{J}_{1}$ is an unknown function and $\mathscr{F}_{2}$ is described by the non-linear equations (9)-(12).

It leads to conclude that the usual introduction of PoD as single parameter in the decision scheme is equivalent to consider that $\mathrm{PoD}=\mathrm{P}(\mathrm{d}(\mathrm{X})=1)$. It implies that two conditions are respected $\{\mathrm{PCP}=1 ; \mathrm{PFA}=0\}$.

Parametric studies can then be performed when modifying the range of PoD, PFA and PCP [17]. In particular, the effect of PFA can be addressed. Thus the transfer of information during inspection can be modelled with successive steps from inspector in laboratory condition to decision-maker. An illustration is given on figure 4 . 


\section{NDT TOOL RANKING BASED ON COST FUNCTION}

Risk based Inspection is devoted to provide to the decisionmaker powerful information to decide which NDT to use, in which part of the structure and when. A complete R.B.I should introduce stochastic model for taking into account the loss of safety with time [9]. As only detection are considered here, the problem is to select N.D.T tool relatively to his performance for a specific application. Costs of inspection and of maintenance policy have to be introduced as well as the so called cost of failure. With respect to the modelling presented on figure 4 several level of decision aid-tools based on NDT tool performance are available :

- PoD based decision aid-tool :

The ranking of techniques is available for a specific range of crack size. A global technique capability upon the total range of crack size is deduced from the area under the PoD curve. A ponderation can be introduced when multipliing each PoD with the PCP of the crack range. The risk is expressed by a summation of the expectation for each cost.

When introducing a systematic repair strategy (repair if detected) the costs to introduce is the cost of inspection $\mathrm{C}_{\mathrm{i}}$, of repair $C_{r}$ and of failure $C_{f}$. . The probability of failure $P f$ is deduced from the consequence of probability of no-crack detection (1 - PoD).

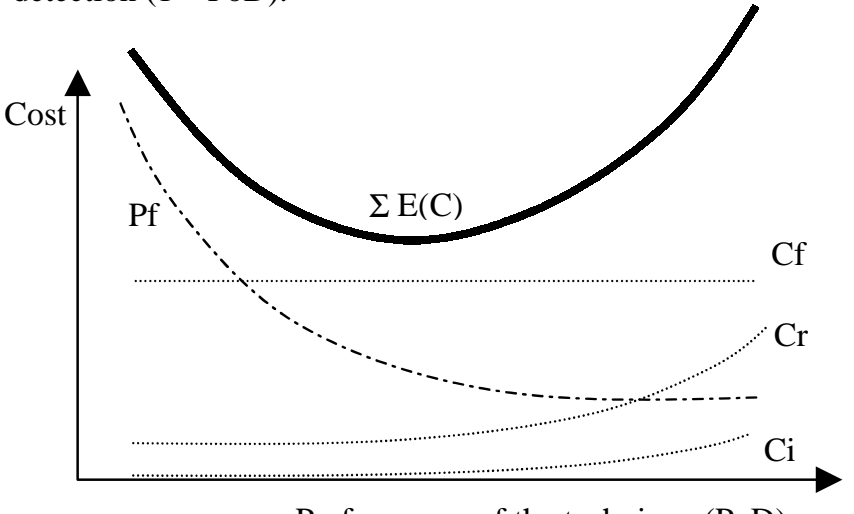

Performance of the technique (PoD)

Figure 5. EFFECT OF P.o.D AS UNIQUE DECISION AIDTOOL.

Moreover, the confidence level on the technique performance can be introduced with the reliability curve. Several conclusions can be deduced in particular about the plot of new P.o.D curves based on sub-populations (typology and depth) or about the modeling of $\mathrm{a}_{\mathrm{d}}$ as a random variable.

- PoD-PFA based decision aid-tool:

Here the couple (PoD,PFA) provides the complete probabilistic information on the tool performance. In fact PoD and PFA are not complementary. The decision is based on the position of the "performance points" on R.O.C curve. An over-cost of repair should be introduced to take into account the displacement of the diver and material at the crack location in case of false alarm. The major difficulty resides in P.F.A assessment based on suitable data.

\section{- P(Ei) based decision aid-tool :}

The probabilities (4)-(7) describe surfaces varying in level with PoD and PFA for specific values of PCP. For a tool which is used in several inspection context (value of $a_{d}$ ), the projection of its R.O.C curve on this surface give a sight of sensitivity to the conditions of inspection. These curves are plotted for the non-complementary probability $\mathrm{P}(\mathrm{E} 2)$ and $\mathrm{P}(\mathrm{E} 3)$ on figures 6 and 7 for two values of PCP (named $\gamma$ ). These values will be commented below in the paper.
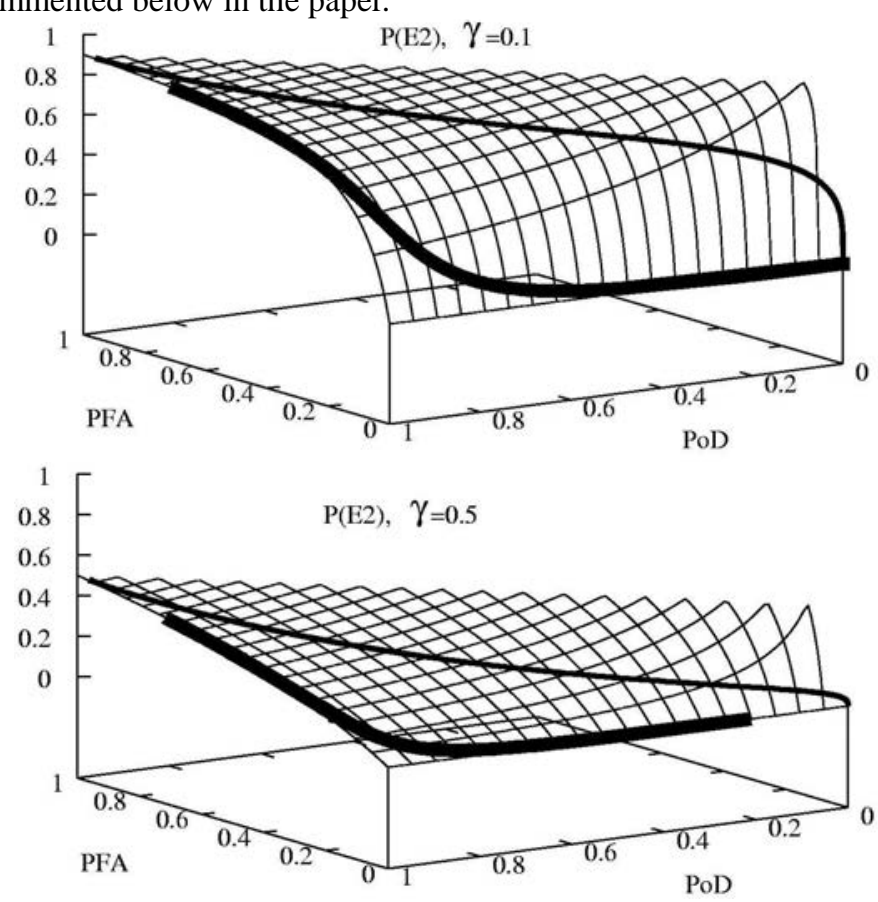

Figure 6. EVOLUTION OF $P\left(E_{2}\right)$ IN THE (PoD ; PFA) plane FOR PCP VALUES OF 0.1 AND 0.5.

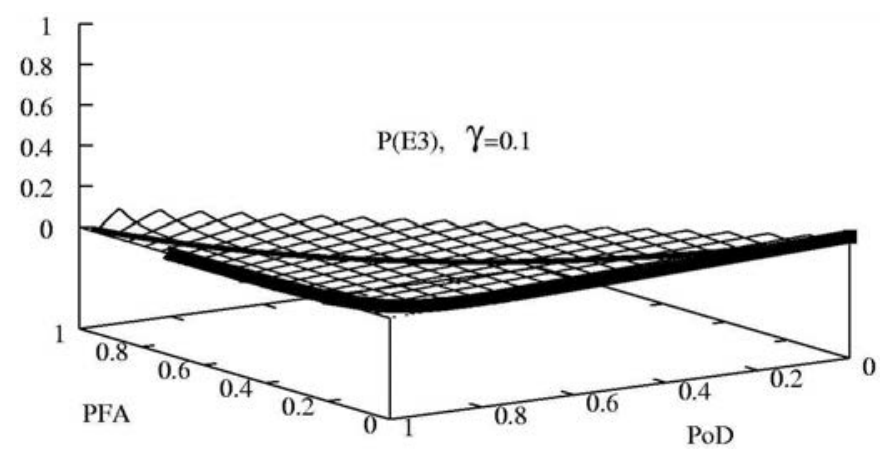




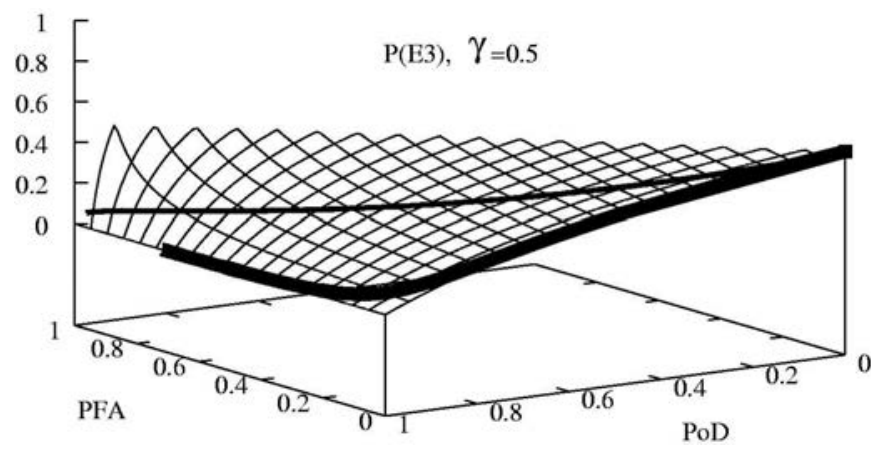

Figure 7. EVOLUTION OF $\mathrm{P}\left(\mathrm{E}_{3}\right)$ IN THE (PoD; PFA) plane FOR PCP VALUES OF 0.1 AND 0.5 .

Let us consider now an utility function based on cost considerations. The expectation of a cost function $\mathrm{E}(\mathrm{C})$ is introduced to this aim [17]. For illustration, the repair strategy is based on the following policy:

- no crack detection leads to no action,

- crack detection leads to repair.

Considering this particular policy, expressions of $\mathrm{E}(\mathrm{C})$ become:

- In case of no crack detection:

$\mathrm{E}(\mathrm{C})=\mathrm{C}_{1}+\overline{\mathrm{C}_{1}} \mathrm{P}\left(\mathrm{E}_{3}\right)$

- In case of crack detection :

$\mathrm{E}(\mathrm{C})=\mathrm{C}_{4} \mathrm{P}\left(\mathrm{E}_{4}\right)+\mathrm{C}_{2} \mathrm{P}\left(\mathrm{E}_{2}\right)$

In this case, the cost overrun is defined by :

$$
\overline{\mathrm{E}(\mathrm{C})}=\mathrm{C}_{2} \mathrm{P}\left(\mathrm{E}_{2}\right)
$$

Where $C_{1}$ is the cost of inspection, $C_{4}$ is the cost including repair in case of crack presence, $C_{2}$ is the cost of inspection and repair and $\overline{\mathrm{C}_{\mathrm{i}}}$ is the cost overrun resulting from bad decisions due to bad inspection results, here the financial penalty due to a non-detected crack (cost of failure). The different relative costs of failure, inspection and repair considered here for illustration are presented in table 1.

The knowledge of these data allows a comparison of the two techniques with performances expressed with the couple (PoD, PFA). Four performances are considered : case (a) and (b) for NDT 1 and case (c) and (d) for NDT 2 (see figure 2 and table 2). The distribution of large cracks is assumed to be exponential with parameter $\lambda=10 \mathrm{~cm}$ and the class range $\delta=$ $5 \mathrm{~cm}$ [18]. Among the two classes [0;5] and [40;45] in centimeter, the values of $\gamma$ are :

$\mathrm{a} \in[0 ; 5] \Rightarrow \gamma=0,4 \quad ; \quad \mathrm{a} \in[40 ; 45] \Rightarrow \gamma=0,01$

These two classes are representative respectively of small and large through cracks. R.O.C are supposed to be constant whatever $\gamma$. The expected costs overrun in case of detection (eq. 17) and the expected cost in case of non-detection are reported in table 2 . The best technique is the one that minimize costs both in case of detection and in case of non-detection.
Here, $\mathrm{C}_{1}=\mathrm{C}_{\text {insp. }} ; \overline{\mathrm{C}_{1}}=\mathrm{C}_{\text {insp. }}+\mathrm{C}_{\text {failure }} ; \mathrm{C}_{2}=\mathrm{C}_{\text {insp. }}+\mathrm{C}_{\text {repair }}$

\begin{tabular}{|c|l|}
\hline Relative costs & Cost level \\
\hline $\mathrm{C}_{\text {failure }}$ & 1.0 \\
\hline $\mathrm{C}_{\text {repair }}$ & 0.02 \\
\hline $\mathrm{C}_{\text {insp, }}$ & 0.002 \\
\hline
\end{tabular}

Table 1. COST HYPOTHESIS.

\begin{tabular}{|c|c|c|c|c|c|c|}
\hline Case & Inspection & $\mathrm{E}(\mathrm{C})$ & $\gamma=0.4$ & $\%$ & $\gamma=0.01$ & $\%$ \\
\hline \multirow[t]{2}{*}{ (a) } & \multirow{2}{*}{$\begin{array}{l}\text { PoD }=0.26 \\
\text { PFA }=0.04\end{array}$} & $\overline{\mathrm{E}(\mathrm{C})})_{\mathrm{d}}$ & 0.0036 & 1 & 0.019 & 70 \\
\hline & & $\mathrm{E}(\mathrm{C}) \mathrm{nd}$ & 0.336 & 99 & 0.008 & 30 \\
\hline \multirow[t]{2}{*}{ (b) } & \multirow{2}{*}{$\begin{array}{l}\text { PoD }=0.66 \\
\text { PFA }=0.31\end{array}$} & $\overline{\mathrm{E}(\mathrm{C})} \mathrm{d}$ & 0.008 & 3 & 0.020 & 77 \\
\hline & & $\mathrm{E}(\mathrm{C}) \mathrm{nd}$ & 0.244 & 97 & 0.006 & 23 \\
\hline \multirow[t]{2}{*}{ (c) } & \multirow{2}{*}{$\begin{array}{l}\mathrm{PoD}=0.99 \\
\mathrm{PFA}=0.04\end{array}$} & $\overline{\mathrm{E}(\mathrm{C})} \mathrm{d}_{\mathrm{d}}$ & 0.001 & 25 & 0.016 & 89 \\
\hline & & $\mathrm{E}(\mathrm{C}) \mathrm{nd}$ & 0.003 & 75 & 0.002 & 11 \\
\hline \multirow[t]{2}{*}{ (d) } & \multirow{2}{*}{$\begin{array}{l}\text { PoD }=0.99 \\
\text { PFA }=0.3\end{array}$} & $\mathrm{E}(\mathrm{C})_{\mathrm{d}}$ & 0.006 & 75 & \begin{tabular}{|l|}
0.019 \\
\end{tabular} & 90 \\
\hline & & $\mathrm{E}(\mathrm{C}) \mathrm{nd}$ & 0.002 & 25 & 0.002 & 10 \\
\hline
\end{tabular}

Table 2. EXPECTED COST DEPENDING ON PoD, PFA, $\gamma$

First, consider the classes of crack size (columns of the table). The third inspection case where the PFA is lower and the PoD greater offers the best compromise in terms of cost whatever $\gamma$. It should be emphasis that having the best PoD do not let to the best NDT tool: PFA affects global performances. Hence, case (d) is not the best choice (high PoD but High PFA too).

Second, consider now each inspection. The more the probability of crack presence is high, the less the PFA plays an important role. That is to say that the cost corresponding to non-detection event is higher in case of large cracks and moreover in case of bad situation of inspection (high PFA).

Third, for low probability of crack presence, the cost overrun in case of crack detection becomes higher and play a dominant role. This effect is more significant with high PFA values. Thus the percentage of the cost over-run in case of detection varies from 3 to $77 \%$ in case (b). More analyses can be deduced from a complete parametric study [17].

It can be difficult to determine precisely the performance point in terms of couple (PoD;PFA). Sensitivity studies can be used to analyse the effect of this uncertainty on the risk. Another way is to consider the mean of probabilities $\mathrm{P}(\mathrm{Ei})$ among the points of the ROC curve. Their mathematical expressions are given in eq. 17.

$$
\left.\mathrm{m}(\mathrm{P}(\mathrm{Ei}))\right|_{\text {ROC }}=\frac{1}{\mathrm{LrOC}} \int_{\text {ROC }} \mathrm{P}(\mathrm{Ei}) \mid \text { IOC } \mathrm{d} \mathrm{l}_{\text {ROC }}
$$

where $1_{\text {ROC }}$ denotes the curvilinear abscissa on the projection of ROC curve on the surface $\mathrm{P}(\mathrm{Ei}), \mathrm{L}_{\mathrm{ROC}}$ the length of the ROC curve in the (PoD;PFA) plane and $\mathrm{P}(\mathrm{Ei})$ / $10 \mathrm{C}_{\text {the }}$ value of $\mathrm{P}(\mathrm{Ei})$ at this abscissa. The corresponding area are drown on figure 8 for $\mathrm{P}\left(\mathrm{E}_{2}\right)$ and NDT 1 and 2. Obviously, these probabilities on the ROC curve are complementary and :

$$
\left.\mathrm{m}(\mathrm{P}(\mathrm{E} 1))\right|_{\mathrm{ROC}}+\left.\mathrm{m}(\mathrm{P}(\mathrm{E} 3))\right|_{\mathrm{ROC}}=1
$$




$$
\left.\mathrm{m}(\mathrm{P}(\mathrm{E} 2))\right|_{\mathrm{ROC}}+\left.\mathrm{m}(\mathrm{P}(\mathrm{E} 4))\right|_{\text {ROC }}=1
$$

Figure 9 presents the same area for $\mathrm{P}\left(\mathrm{E}_{3}\right)$ where the discrepancy between the areas obtained for the two NDT are not so large.
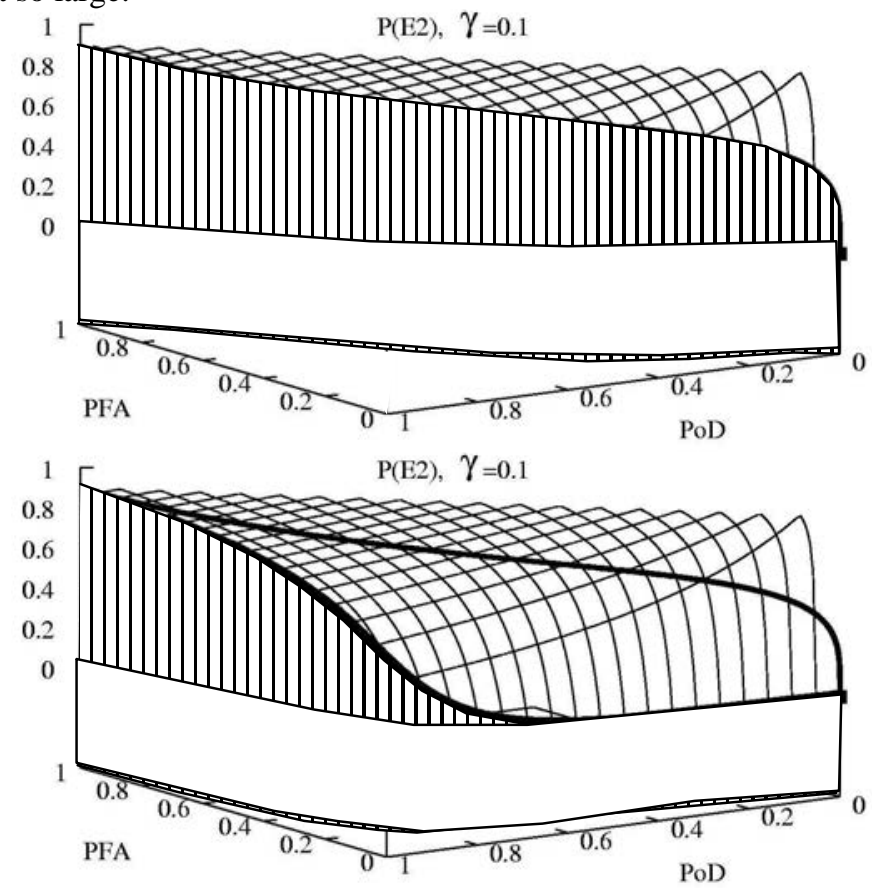

Figure 8. INTEGRATED AREA OF P(E2) FOR NDT 1 (upon) and 2 (below).
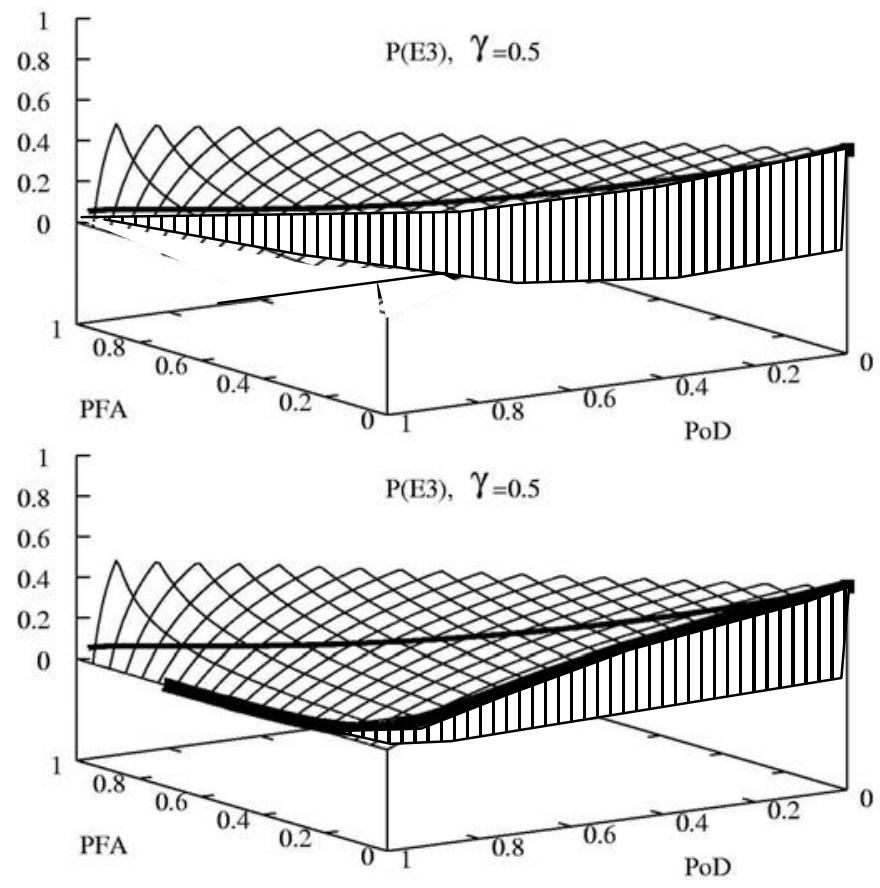

Figure 9. INTEGRATED AREA OF P(E3) FOR NDT 1 (upon) and 2 (below).
The mean expected cost on the ROC curve has the convenient form (deduced from eq. 16 and 17):

- In case of no crack detection:

$\mathrm{E}(\mathrm{C})=\mathrm{C}_{1}+\left.\overline{\mathrm{C}_{1}} \mathrm{~m}\left(\mathrm{P}\left(\mathrm{E}_{3}\right)\right)\right|_{\text {ROC }}$

- In case of crack detection :

$$
\mathrm{E}(\mathrm{C})=\left.\mathrm{C}_{4} \mathrm{~m}\left(\mathrm{P}\left(\mathrm{E}_{4}\right)\right)\right|_{\text {ROC }}+\left.\mathrm{C}_{2} \mathrm{~m}\left(\mathrm{P}\left(\mathrm{E}_{2}\right)\right)\right|_{\text {ROC }}
$$

Table 3 presents results obtained for $\mathrm{L}_{\mathrm{ROC}}$, length of ROC curve in the plane (PFA;PoD), $\mathrm{m}(\mathrm{PE} 3), \mathrm{m}(\mathrm{PE} 2), \overline{\mathrm{E}(\mathrm{C})})_{\mathrm{d}}$ and $\mathrm{E}(\mathrm{C})_{\mathrm{nd}}$.

\begin{tabular}{|l|l||l||l||l|l|}
\hline Inspection & $\mathrm{L}_{\mathrm{ROC}}$ & $\mathrm{m}(\mathrm{PE} 3)$ & $\mathrm{m}(\mathrm{PE} 2)$ & $\overline{\mathrm{E}(\mathrm{C})})_{\mathrm{d}}$ & $\mathrm{E}(\mathrm{C})_{\mathrm{nd}}$ \\
\hline $\begin{array}{l}\text { NDT } 1 \\
\gamma=0.4\end{array}$ & 1.51 & 0.257 & 0.766 & 0.017 & 0.26 \\
\hline $\begin{array}{l}\text { NDT 2 } \\
\gamma=0.4\end{array}$ & 1.89 & 0.1273 & 0.87 & 0.019 & 0.13 \\
\hline $\begin{array}{l}\text { NDT 1 } \\
\gamma=0.01\end{array}$ & 1.51 & 0.0033 & 0.995 & 0.022 & 0.009 \\
\hline $\begin{array}{l}\text { NDT 2 } \\
\gamma=0.01\end{array}$ & 1.89 & 0.002 & 1 & 0.022 & 0.004 \\
\hline
\end{tabular}

Table 3. EXPECTED MEAN COST OVER ROC

\begin{tabular}{|l||l|l|}
\hline Inspection & $\mathrm{E}(\mathrm{C})_{\mathrm{d}}$ & $\mathrm{E}(\mathrm{C})_{\text {nd }}$ \\
\hline NDT $1 ; \gamma=0.4$ & 0.017 & 0.26 \\
\hline NDT $2 ; \gamma=0.4$ & 0.021 & 0.13 \\
\hline NDT $1 ; \gamma=0.01$ & 0.022 & 0.009 \\
\hline NDT $2 ; \gamma=0.01$ & 0.024 & 0.006 \\
\hline
\end{tabular}

\section{Table 4. EXPECTED MEAN COST OVER ROC}

It allows a global overview of the NDT performance. It leads to conclude that these tools are equivalent in case of large cracks and that the cost in case of non detection is globally higher for small cracks. NDT 1 appears to lead to higher costover-run for this range of cracks. This analysis must be completed by introducing a difference between the costs of the both inspections. If NDT 1 keeps the same value of 0.002 and NDT 2 which has "a better ROC" a cost of 0.004 , then the last columns of table 3 is modified and presented in table 4 .

The analysis of cots for small cracks detection is particularly interesting under this hypothesis. In fact, tools 1 and 2 lead to the same cost over-run and are similar in terms of risk analysis. This conclusion is of interest beacause of the price of FMD (Flooded Member Detection) which is low with PFA which are low too. More studies should investigate the assessment of PFA. 


\section{CONCLUSION}

The use of NDT when inspecting existing structures leads to state the importance of a probabilistic modeling. In this paper the detection is pointed out with specific definition of the PoD and PFA. An cost function based on a mean performance of NDT tool is proposed and shown to be very suitable for ranking purposes whether of the inspection performance tools. This decision aid-tool can be introduced as an alternative to other classical aid-tools especially in the cases where the uncertainty on ROC points position is significant. It leads to conclude that better PoD cuves don't lead to better NDT tool in terms of risk analysis. PFA acts as important parameter.

\section{ACKNOWLEDGMENTS}

The work reported here had been carried out in collaboration with IFREMER. Its support is gratefully acknowledged.

\section{REFERENCES}

[1] Goyet J., Faber M.H. Integration Approach for RBI of offshore installations. In international workshop on reliability and risk based inspection planning, ETH, Zürich, Suisse.(2000)

[2] Guoyang Jiao. Reliability analysis of crack growth with inspection planning. In proceeding of the $11^{\text {th }}$ International Conference on Offshore Mechanics and Arctic Engineering, Vol. 3, ASME, editor, New York.( 1992).

[3] Moan T., Johannesen J.M., Vårdal O.T. 1999. Probabilistic Inspection Planning of Jacket Structures. In Proceedings of the Offshore Technology Conference, OTC Paper $\mathrm{N}^{\circ} 10848$, Houston, Texas, USA.

[4] Bloch A., S申rensen J.D, Faber M.H. Simplified approach to inspection planning. In $8^{\text {th }}$ ASCE Specialty Conference on Probabilistic Mechanics and Structural Reliability (2000)

[5] Faber M., Sorensen J.D. Aspects of inspection planning quality. In Melchers R.E., Stewart M.G., editor, Application of Statistics and Probability, pages 739-746. ISBN 9-0580-9086-8.( 1999).

[6] Goyet J., Paygnard J.C., Maroini A., Faber M.H. 1994. Optimal inspection and repair planning: case studies using IMREL software. In New York ASME, editor, Proceeding of the $13^{\text {th }}$ International Conference on Offshore Mechanics and Arctic Engineering, volume 2.

[7] Faber M.H. 2000. Risk based inspection - the framework. In International workshop on reliability and risk based inspection planning, ETH, Zurich, Suisse.

[8] Tanaka H., Toyoda-Makino M. Cost based optimal relation between inspection time and assessment time for random fatigue crack growth. Probabilistic engineering, 13(2): 69-76.( 1996).

[9] Madsen H.O. Stochastic modeling of fatigue crack growth and inspection. In Probabilistic Methods For Structural Design, collection Solid Mechanics and its applications, pp. 59-83, Guedes Soares (Ed), Kluwer academic publisher.(1997).

[10] Jiao G. Reliability analysis of crack growth with inspection planning. In Proceeding of the $11^{\text {th }}$ International Conference on Offshore Mechanics and Arctic Engineering, volume 2, pages 227-235.( 1992).

[11] Onoufriou T. Reliability based inspection planning of offshore structures. Marine structures, 12:521-539.( 1999).

[12] Reicks W.J., Burt R., Mazurana J., Steinle R.J. 2000. USCGC Healy (WAGB 20) - A case study for implementing Reliability Centered Maintenance. Marine Technology, Vol. 37, $\mathrm{N}^{\circ} 1$.

[13] Barnouin B., Lemoine L, Dovetr W.D., Rudlin J., Fabbri S., Rebourcet G., Topp D., Kare R., Sangouard D. Underwater inspection reliability trials foroffshore structures. Proc. Of the $12^{\text {th }}$ International Conference on Offshore Mechanics and Arctic Engineering. Vol. 2 pp. 883-890 NY ASME ed. (1993).

[14] Rudlin J.R. Reliability of inspection for fatigue cracks in offshore structures. Institution of Electrical Engineers, Savoy Place, London WC2R OBL, UK. 6/1-6/3 (1996). .

[15] Schoefs F, Rouhan A, Goyet J. 2001. Risk-Based Inspection on in-service offshore platforms : a probabilistic approach of the crack detection and global integrity criteria, ICOSSAR'01 8th International Conference on Structural Safety and Reliability, Newport Beach, California, USA. 8 pages.

[16] Rouhan A. 2001. Structural integrity evaluation of existing offshore platforms based on inspection data. Phd, thesis, University of Nantes, France.

[17] Rouhan A., Schoefs F. 2002. Probabilistic modelling of inspections results for offshore structures. Structural safety - accepted.

[18] Moan T., Vårdal O.T., Hellevig N.C, Skjoldli. 1997. InService Observations of Cracks In North Sea Jackets. A Study on Initial Crack Depth and POD values. In Proceeding of 16th international conference on Offshore Mechanics and Arctic Engineering, (O.M.A.E'97), Vol. II Safety and Reliability, pp. 189-197. New York ASME,

[19] Pedersen C., Nielsen J.A., Riber J.P., Madsen H.O., Krenk S., 1993. Reliability Based Inspection Planning for the Tyra Field. In Proceeding of the $12^{\text {th }}$ International Conference on Offshore Mechanics and Arctic Engineering, New York ASME, editor. 